made in the Bill for an increase in the vote for the Scottish Universities:-

"The increase of $£, I 3,000$ in the vote was no striking example of Parliamentary generosity when measured by the efforts of other countries. Reference had been made to what had been done in Holland, a country with a revenue of nine millions, and a population about the same as that of Scotland. Holland gave £i36,000 to her Universities. The case of France was equally striking. The French Institute discussed for a whole week why it was that the great crisis in her history produced no men of ability in France. The decision they came to was that the reason was to be found in the decay of the provincial Universities. Since that time the French Government had spent $£ 3,280$,ooo on the provincial Universities, and voted half a million a year for their support. Then Germany had spent $£ 7$ I1,000 in order to build and equip the University of Strasburg, which they endowed with $£ 46$, ooo a year. This country must be preparea' to spend more money on higher education not only in Scotland, but in England. Modest, however, as was the proposal of the Government, he was rejoiced at the disappearance of the abominable finality clause. There was no finality in knowledge or the progress of science. Notwithstanding the stern aspect of the Chancellor of the Exchequer, we could not help ourselves. We must be prepared to adequately support our Universities, and to make sufficient provision for higher teaching in all our great towns. Though he thought the provision inadequate for what the Bill proposed, he had perfect confidence in the generosity of Parliament that, having begun the reform of the Scotch Universities, they would take care that the reform was thoroughgoing. In the Scotch Universities, while the number of students was very large relatively to the number of teachers as compared with, say, the German Universities, they had one Professor for one single subject. For the Chair of Chemistry in Edinburgh, for example-a chair which he had had the honour to hold-there was but one Professor, whereas in any moderate-sized German University there were four or five. They must add largely to the teaching staff of the Universities in Scotland if they expected them to become prosperous. . . . The teaching Universities in England had one student to 3500 of the population; in Ireland there was one student to 2040 of the population; while in Scotland there was one University student to 580 of the population. Therefore, the roots of University education had gone seven times wider and broader among the people of Scotland than they had done either in England or in Ireland. The object had always been to try and evolve brain power from all capable citizens, and it was this which had made Scotland what it was. Nevertheless, it was his deliberate opinion that Scotland was decidedly behind England in education. The English Universities had been adapting themselves to the changing conditions of the world very largely, and the Scottish Universities had been remaining behind in modern wants altogether. The lion rampant in Scotland had been standing on its hind legs pawing the air, while the lion passant with its fore-feet on the ground had been going ahead; and it was because of that consideration that he was extremely anxious to see this Bill pass into law."

\section{THE OXFORD UNIVERSITY OBSERVATORY.}

THE Savilian Professor of Astronomy, in his Annual 1 Report, read on June 5, thus refers to the work In additio

In addition to the statutable lectures, four others were given on the recent speculations concerning the construction of the sidereal universe, in relation to possible meteoric collisions.

The renovation of the macro-micrometer, mentioned in the last Report, has been completed by Mr. Simms, who originally constructed it; and it has since been in constant use. The mounting of the De la Rue instrument has been provided with a slow motion in right ascension, of a peculiar and delicate construction, and set in motion by electro-magnets; the driving-clock also has been thoroughly renovated in the parts which exhibited the effects of wear. The object of all these extensive improvements is to make it possible to expose photographic plates during those lengthened periods of several hours, rendered necessary for the purposes of the recent modifications of astronomical inquiries. These improvements have been so recently effected, and the twilight is at present so protracted, that it has not yet been possible to fully test their practical efficiency on the skies.

The mounting of the Grubb equatorial has been completed. It is now furnished with automatic driving apparatus of the most modern and efficient construction, well worthy of the high reputation of its eminent constructor. The visual object-glass has been refigured, and is now in a greatly improved condition. The tube of the photographic telescope is in situ, but the object-glass of I 3 inches' aperture, meeting the conditions required by the International Congress, has not yet been supplied by the maker. Two experimental object-glasses have, however, been already examined, but their performance did not prove satisfactory. Prof. Pritchard is now expecting the speedy arrival of a third, which, he is assured by Sir Howard Grubb, will relieve him from further anxiety, and place him in a position to prosecute the essential preliminary operations necessary for the International scheme.

All these important renovations and additions, so necessary to practical astronomy in its present phase, have been provided by the unsolicited generosity of the late Dr. De la Rue. Prof. Pritchard expresses deep regret -which he has no doubt is shared by the Board of Visitors - that their lamented and munificent friend did not live, as he had hoped, to see the fulfilment of his anticipations in connection with this judicious expenditure.

The first extensive series of the observations connected with the new application of the photographic method to stellar parallax, as applied to stars of the second magnitude in the northern hemisphere, has been brought to a conclusion, and is now, through the liberality of the Delegates of the University Press, in course of printing. The volume, it is hoped, will be distributed among astronomers in the course of a few weeks. It comprises no less than thirty distinct determinations of stellar parallax : these are applied to eight stars, referred in most cases to four faint stars of comparison. Progress also has been made in the continuation of the like observations to other stars connected with the general scheme. Prof. Pritchard has had the gratification of finding that this method of parallactic determination, which was originally devised at Oxford, is in process of adoption at other well-known Observatories.

At the request of Dr. Gill, he proposes to assist in a scheme of photographic observation of the minor planet Victoria, for the determination of solar parallax during the present summer ; efficient assistance, however, can be rendered in this direction only on the condition of the arrival of a satisfactory object-glass from Dublin.

He has been engaged in the examination of a Wedge photometer for the Observatory of Pulkova at the instance of its eminent Director. It is not without some satisfaction that he finds that this method of photometry is likely to be employed in other Observatories.

The Director states that the various operations mentioned above could not have been thus efficiently completed without the continuous and intelligent co-operation of the two able assistants, Mr. W. E. Plummer and Mr. C. A. Jenkins. It has been a source of great gratification 
to him that Mr. Plummer's ability has been recognized by the Royal Astronomical Society in their selection of him for a seat on their Council.

\section{JOHN PERCY, M.D., F.R.S.}

$\mathrm{B}$ the death of Dr. Percy, on the rgth inst, this country has lost a distinguished man, who has greatly influenced its metallurgical progress.

He was born in 1817 , and at an early age entered the Medical School of the University of Edinburgh, where, at twenty-one, he took the degree of M.D. He subsequently became Physician to the Queen's Hospital at Birmingham, and the few papers he published on medical subjects show that he would probably have risen to eminence in medicine had it not been for the fact that in the great metallurgical centre of the Midlands his studies were soon diverted to the particular line of work to which his life was ultimately devoted. This is not perhaps surprising when it is remembered that the connection between therapeutics and metallurgy has been traditional since the days of Paracelsus and Agricola.

When we look back at Dr. Percy's career, the remarkable fact stands out that notwithstanding the great importance of metallurgy to this country, with its vast industrial interests, there was no metallurgical treatise worthy of the name until he wrote one; and, what is stranger still, up to the time when he accepted the chair in the Royal School of Mines, in $185 \mathrm{I}$, there was no systematic teaching of metallurgy. Dr. Percy found it practised mainly as an empirical art. Sir Henry de la Beche indicated the direction the teaching had to take, and in his inaugural discourse as Director of the School of Mines, he said, "We still too frequently hear of practical knowledge as if, in a certain sense, it were opposed to a scientific method of accounting for it, and as if experience without scientific knowledge were more trustworthy than the like experience with it." Reference to the pages of the Journal of the Iron and Steel Institute will show that this, the most practical body of men in the world, not only thoroughly recognizes that mere empiricism would be fatal to industrial success, but constantly appeals to science for guidance. This is in great measure owing to Dr. Percy's teaching, and is not the least important of its results.

Ten years after he began to teach, he published the first volume of his treatise on "Metallurgy," which he dedicated with "sincere respect and affectionate regard" to Faraday. This work, which he calls the "task of his life," has developed into a series of volumes containing 3500 octavo pages. One remarkable feature of these books is that almost every woodcut may he regarded as an accurate, though small, mechanical drawing, and it is only measurable drawings of this kind which are of real utility in practice. Treatises such as his naturally embody descriptions of processes furnished by those actually engaged in conducting the operations-aid which was always most fully acknowledged. The thoroughness of his own research is well shown by the careful digests of monographs, which were gathered from all kinds of sources; and it is evident that immense pains were bestowed upon the work. Some years ago a foreign friend, 'himself a laborious and conscientious author, forcibly expressed to the writer his appreciation of Dr. Percy's labours, looking up from one of the volumes and exclaiming, "C"est énorme ce qu'il a compilé."

It may perhaps be admitted that his intolerance of inaccuracy at times led him to magnify points which now seem to be somewhat trivial, and he sometimes withholds the expression of his own opinion when the reader has fairly a right to expect it, and would be grateful for the support of his authority.

With the notable exception of a process for the extraction of silver from argentiferous ores and residues, he can hardly be said to have originated any important metallurgical process; but his works teem with suggestions, and many improvements in metallurgical practice can be directly traced to his teaching. Such is the case with the practical application of the basic process for eliminating phosphorus in the Bessemer converter-a process of truly national importance, and one which has been widely adopted in other countries. It may fairly be claimed that during the thirty years he held his chair he trained a body of scientific workers in whose hands the immediate future of metallurgy to a great extent rests.

Remarkable evidence as to the strength of his individuality is afforded by the fact that those who were admitted to his friendship, and even his students who only saw him in the lecture-room or laboratory, were all singularly attracted to him, notwithstanding the occasional ruggedness of his manner. The purity of his style and the quaintness of his illustration recall the writings of another doctor, Sir Thomas Browne, making, of course, due allowance for the difference of the periods at which they wrote. The subjects he dealt with were very diverse, and it would be interesting to collect his trenchant letters, which appeared in the Times, usually over the signature Y. One especially occurs to the writer. Dr. Percy was charged with the superintendence of the ventilation of the Houses of Parliament, and amusingly describes his difficulties in meeting the varied and often contradictory requirements of the members, as to the temperature best suited to their work. He was an honorary member of the Institution of Civil Engineers, and held the office of President of the Iron and Steel Institute in 1885, having received the Bessemer Medal of that Institute in 1877 . His artistic skill was considerable, and he possessed a fine collection of water-colour drawings.

Two days before his death the Prince of Wales awarded him, on the nomination of the Council, the Albert Medal of the Society of Arts. Dr. Percy was still able to appreciate the honour which had been done him, and received the intimation with the characteristic words, almost his last, "My work is done."

W. C. Roberts-Austen.

\section{HENRY WILLIAM BRISTOW, F.R.S.}

$\mathrm{M}^{\mathrm{R}}$ R. BRISTOW'S death, which we briefly chronicled last week, requires a fuller notice. With him passes away one of the gentlest and most courteous of English geologists-one whose associations connected him with the magnates of geology in the early decades of this century, and whose death breaks another of the links that unite us personally with that heroic time. Born in 1817 , he was the only son of Major-General H. Bristow, a distinguished officer, who devoted himself to the cause of Spain, where he died, and received the honours of a public funeral. Mr. Bristow suffered from an inveterate deafness. An old school-fellow, speaking of his boyish days not long ago, remarked that he was as deaf then as he was even late in life. This ailment was undoubtedly a life-long hindrance to him, for it kept him from mingling as freely among his associates, and taking so public a part, as his tastes and abilities would have prompted and fitted him to do.

When twenty-five years of age, he joined the Geological Survey under Sir Henry De la Beche, and he remained in that department of the public service for the long space of forty-six years. Most of his scientific work was done for the Survey, and is to be found in the official maps, sections, and memoirs. It is thus, perhaps, less generally known than that of some of his colleagues who have published communications in the more widely circulated scientific journals. To those, however, who can appreciate accurate and artistic mapping, the work which he did, more particularly among the Secondary rocks of 